\title{
Observation of an Fe(II) Spin-Crossover in a Cesium Iron Hexacyanochromate
}

\author{
Wataru Kosaka, ${ }^{\dagger}$ Kiyoshi Nomura, ${ }^{\dagger}$ Kazuhito Hashimoto, ${ }^{*}{ }^{\dagger}$ and Shin-ichi Ohkoshi*,+, \\ ${ }^{\dagger}$ Department of Applied Chemistry, School of Engineering, The University of Tokyo, \\ 7-3-1 Hongo, Bunkyo-ku, Tokyo 113-8656, Japan \\ ${ }^{\ddagger}$ PRESTO, JST, 4-1-8 Honcho Kawaguchi, Saitama 332-0012, Japan \\ e-mail: ohkoshi@light.t.u-tokyo.ac.jp
}

SUPPORTING INFORMATION

\section{SEM image:}

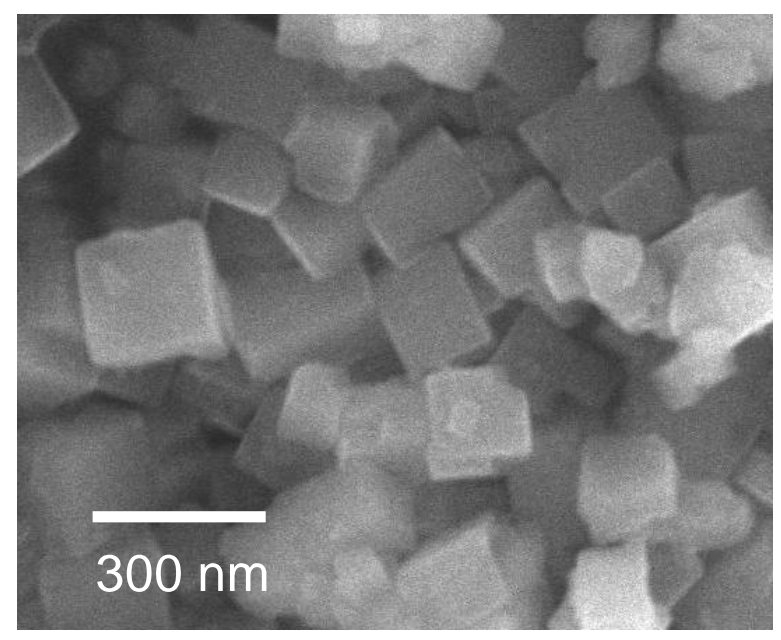

Figure $\mathrm{S} 1$. SEM image of the $\mathrm{CsFeCr}(\mathrm{CN})_{6} \cdot 1.3 \mathrm{H}_{2} \mathrm{O}$ 


\section{${ }^{57}$ Fe Mössbauer spectra of HT and LT phases:}

At $235 \mathrm{~K}$, a doublet peak (I) was mainly observed (85\%), which is assigned to $\mathrm{Fe}^{\mathrm{II}}{ }_{h s}$. At 170 $\mathrm{K}$, this doublet peak disappeared and a singlet peak (II) appeared, which is assigned to $\mathrm{Fe}^{\mathrm{II}}{ }_{l s}$. These results show that the spin crossover actually occurred on $\mathrm{Fe}^{\mathrm{II}}$ sites. A small doublet peak (III) and a singlet peak (IV) were observed at both temperatures. The peak (III) is assigned to the remaining $\mathrm{Fe}^{\mathrm{II}}{ }_{h s}$ in LT phase, and the peak (IV) is assigned to $\mathrm{Fe}^{\mathrm{II}}{ }_{l s}$ of cyano flip.

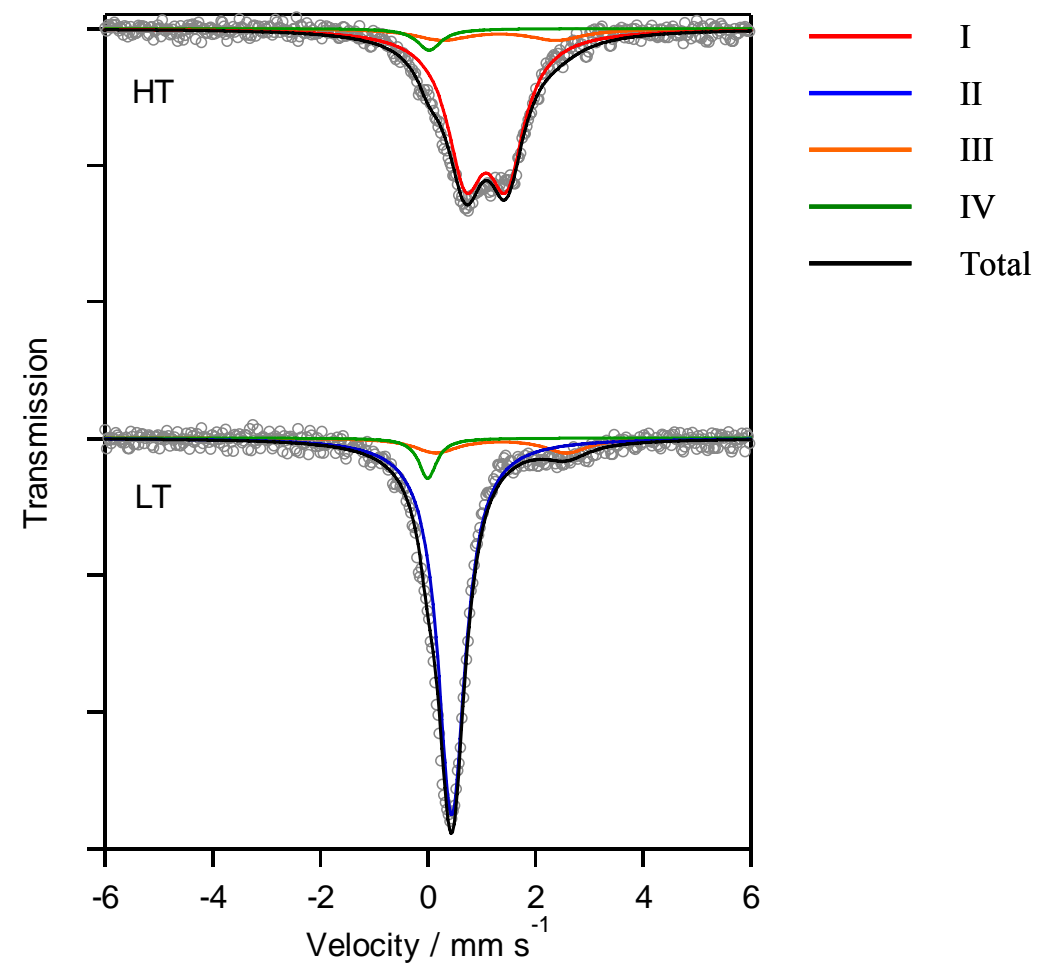

Figure S2. ${ }^{57} \mathrm{Fe}$ Mössbauer spectra of HT phase (235 K) and LT phase (170 K) in the cooling process.

Table S1. ${ }^{57} \mathrm{Fe}$ Mössbauer parameters of HT phase and LT phase.

\begin{tabular}{cccccccc}
\hline & \multicolumn{3}{c}{ HT phase $(235 \mathrm{~K})$} & \multicolumn{3}{c}{ LT phase $(170 \mathrm{~K})$} \\
& area & IS & QS & area & IS & QS & assignment \\
\hline I & $85 \%$ & 1.07 & 0.74 & - & - & - & $\mathrm{Fe}^{\mathrm{II}}{ }_{h s}-\mathrm{NC}$ \\
II & - & - & - & $84 \%$ & 0.44 & 0 & $\mathrm{Fe}^{\mathrm{II}}{ }_{l s}-\mathrm{NC}$ \\
III & $10 \%$ & 1.32 & 2.12 & $10 \%$ & 1.36 & 2.43 & $\mathrm{Fe}^{\mathrm{II}}{ }_{h s}-\mathrm{NC}$ \\
IV & $5 \%$ & 0.02 & 0 & $6 \%$ & -0.01 & 0 & $\mathrm{Fe}^{\mathrm{II}}{ }_{l s}-\mathrm{CN}$ \\
\hline
\end{tabular}




\section{Statistical probabilities of coordinate geometries around $\mathrm{Fe}$ in $\mathrm{Fe}\left[\mathrm{Cr}(\mathrm{CN})_{6}\right]_{2 / 3} \cdot 5 \mathrm{H}_{2} \mathrm{O}$ :}

In $\mathrm{Fe}^{\mathrm{II}}\left[\mathrm{Cr}^{\mathrm{III}}(\mathrm{CN})_{6}\right]_{2 / 3} \cdot 5 \mathrm{H}_{2} \mathrm{O}$, vacancies randomly exist in the lattice as shown in Figure $\mathrm{S} 3$. The statistical probabilities of $\mathrm{Fe}^{\mathrm{II}} \mathrm{N}_{6}, \mathrm{Fe}^{\mathrm{II}} \mathrm{N}_{5} \mathrm{O}, \mathrm{Fe}^{\mathrm{II}} \mathrm{N}_{4} \mathrm{O}_{2}, \mathrm{Fe}^{\mathrm{II}} \mathrm{N}_{3} \mathrm{O}_{3}, \mathrm{Fe}^{\mathrm{II}} \mathrm{N}_{2} \mathrm{O}_{4}$, and $\mathrm{Fe}^{\mathrm{II}} \mathrm{NO}_{5}$ are expressed by the product of the combination $\left({ }_{6} \mathrm{C}_{n} ; \mathrm{n}=0-5\right)$ and existing probabilities of $1 / 3$ and $2 / 3$ for $\mathrm{O}$ and $\mathrm{N}$ atoms, that is, ${ }_{6} \mathrm{C}_{\mathrm{n}}(1 / 3)^{\mathrm{n}}\left(\mathrm{C}^{2} / 3\right)^{6-\mathrm{n}}$, where $\mathrm{n}$ is the number of $\mathrm{O}$ atoms.

(a)

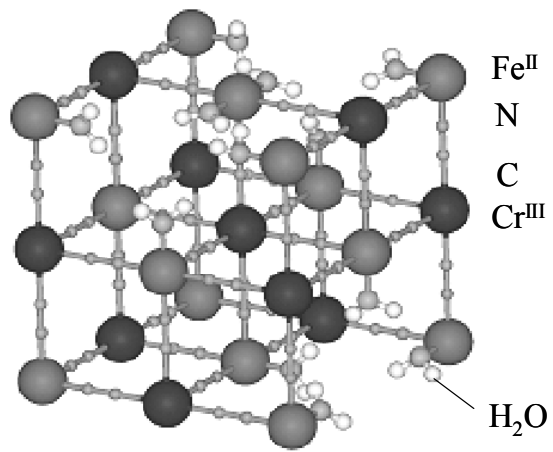

(b)

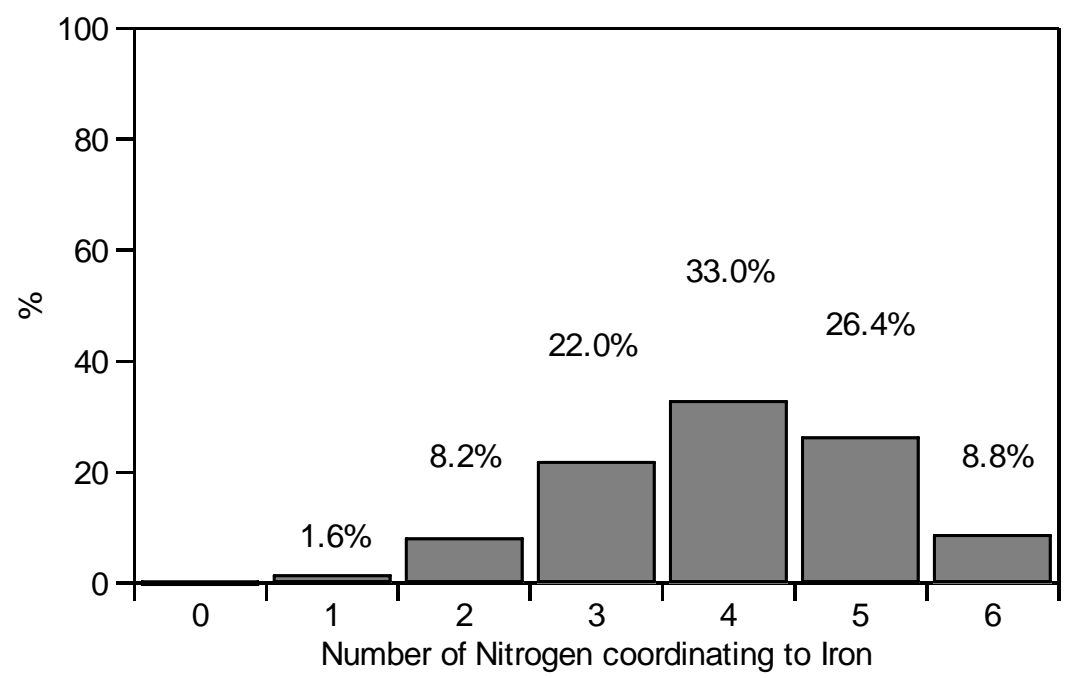

Figure S3. (a) Schematic illustration of the crystal structure of $\mathrm{Fe}^{\mathrm{II}}\left[\mathrm{Cr}^{\mathrm{III}}(\mathrm{CN})_{6}\right]_{2 / 3} \cdot 5 \mathrm{H}_{2} \mathrm{O}$. Ligand water molecules coordinate to $\mathrm{Fe}^{\mathrm{II}}$ around the vacancies of $\left[\mathrm{Cr}^{\mathrm{III}}(\mathrm{CN})_{6}\right]$. Zeolitic water molecules are here omitted. (b) The statistical probabilities of possible coordinating geometries around $\mathrm{Fe}^{\mathrm{II}}$. 


\section{Analysis of $\chi_{\mathrm{M}} T-T$ curves:}

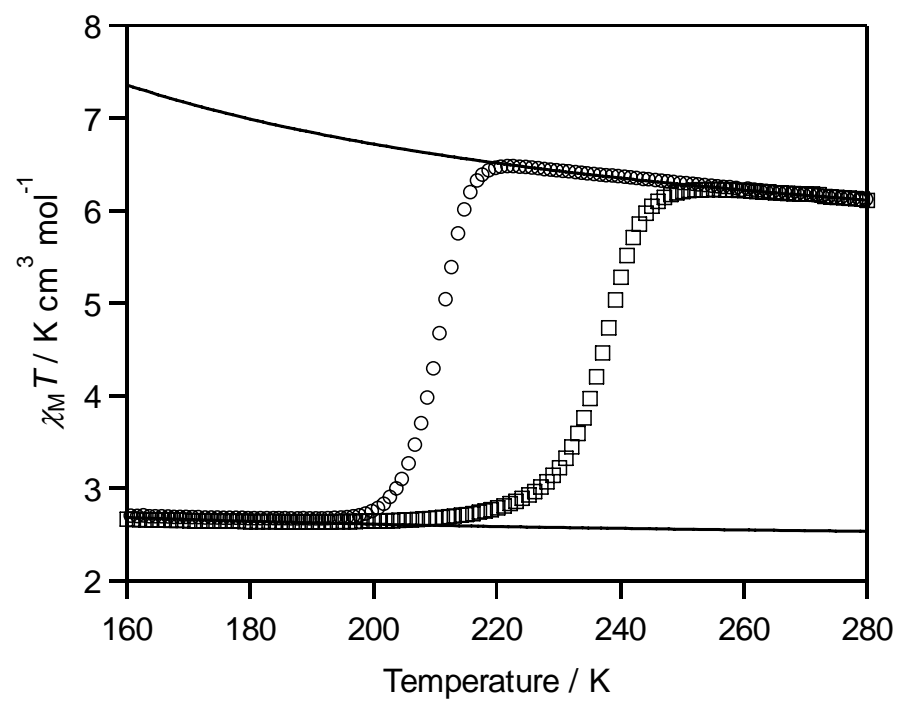

Figure S4. The analysis of the $\chi_{\mathrm{M}} T-T$ curves of HT and LT phases using a molecular field theory, i.e., HT phase ( $\left.\mathrm{Fe}^{\mathrm{II}}{ }_{h s}: S=2, \mathrm{Cr}^{\mathrm{III}}: S=3 / 2\right)$ with $J_{\mathrm{FeCr}}=+1.9 \mathrm{~cm}^{-1}, g_{\mathrm{Fe}}=2.1$, and $g_{\mathrm{Cr}}=2.0$, and LT phase ( $\left.89 \% \mathrm{Fe}^{\mathrm{II}}{ }_{l s}: S=0,11 \% \mathrm{Fe}^{\mathrm{II}}{ }_{h s}: S=2: \mathrm{Cr}^{\mathrm{III}}: S=3 / 2\right)$ with $J_{\mathrm{CrCr}}=+1.1 \mathrm{~cm}^{-1}, g_{\mathrm{Fe}}=2.1$, and $g_{\mathrm{Cr}}$ $=2.0$.

\section{Magnetic property of LT phase:}
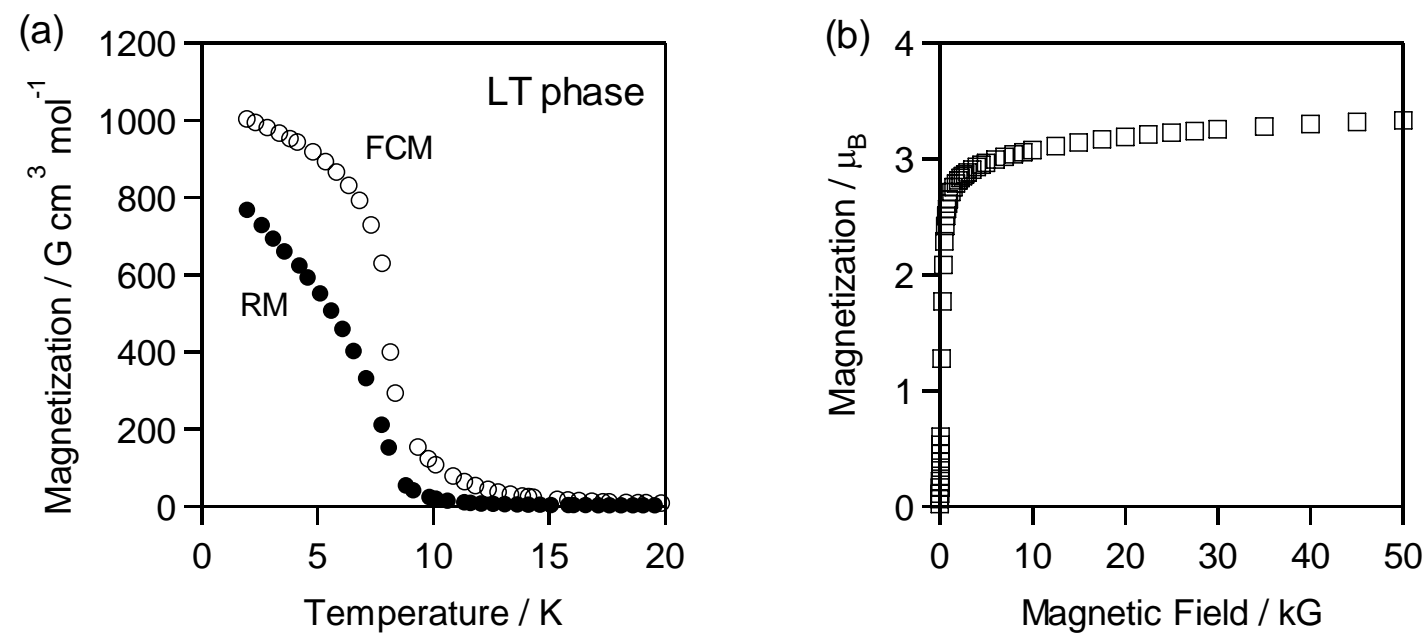

Figure S5. (a) Field-cooled magnetization (FCM) and remnant magnetization (RM) curves of the LT phase in an external magnetic field of $10 \mathrm{G}$. (b) Magnetization vs. external magnetic field plots of the LT phase at $2 \mathrm{~K}$. 